\title{
Curve Estimation Models for Estimation and Prediction of Impact Factor and CiteScore Using the Journal Percentiles: A Case Study of Telecommunication Journals
}

\author{
https://doi.org/10.3991/ijoe.v15i14.11373 \\ Hilary I. Okagbue ${ }^{(凶)}$, Patience I. Adamu, Sheila A. Bishop, \\ Covenant University, Ota, Nigeria \\ hilary.okagbuedcovenantuniversity.edu.ng \\ Emmanuela C. M. Obasi \\ Federal University, Otuoke, Nigeria \\ Adedotun O. Akinola \\ Covenant University, Ota, Nigeria
}

\begin{abstract}
The impact factor and CiteScore of journals are known to be positively correlated with journal percentile but the use of the later to predict the formers are scarcely discussed, especially for journals in a specific subject classification based on the web of science. This paper proposed different curve estimation models for predicting the impact factor and CiteScore of 89 telecommunication journals using their corresponding percentiles. Out of the 11 models, only Logistic, exponential, Growth and Compound models are the best models for predicting the impact factor and CiteScore using their corresponding journal percentiles. The models were chosen because of their high values of $\mathrm{R}$ Square and Adjusted R Square and low values of the standard error of the estimates. In addition, strong significant positive correlations were obtained between impact factor and the CiteScore of the journals. The findings will help authors and editors in decision making as regards to manuscript submission and planning.
\end{abstract}

Keywords - Impact factor, CiteScore, Quartiles, Percentiles, curve estimation, ranking analytics, statistics.

\section{Introduction}

In all the bibliometric metrics used in journal evaluation, impact factor and CiteScore are the leading ones. Impact factor is exclusive to the web of science managed by Clarivate Analytics. Science Citation Index, Social Science Citation Index, and Arts and Humanities Index are journals with impact factors. On the other hand, CiteScore is exclusive to Scopus and is managed by Elsevier. Both impact factor and CiteScore are employed in the evaluation of impact, prestige and quality of 
journals. Similar metrics like h-index and i10-index are used for researchers' evaluation. The combination of different metrics is often used in journal evaluation [1].

Bibliometric is used in different aspects of academics, such as in the evaluation of research outputs of individuals, universities and countries [2-5]. Academic ranking bodies used bibliometric data as part of the criteria for evaluating the reliability of teaching and research of academic organizations [6-8]. Apart from ranking, the bibliometric information can be used evaluation of editorship of journals, decision making before manuscript submission, recruitment of academic staff and their subsequent promotions, assessment of investigators during grant evaluation, development of new academic fields, auditing of journals and detection of predatory attributes [9-13].

This work presents the predictive models that can be used to estimate the impact factor or CiteScore of 89 telecommunication journals using their percentiles. The telecommunication journals publish articles of the following scope: telecommunication system analysis, modulation and coding, multiple access techniques, broadband wireless communications, wireless sensor networks, speech and image coding, detection and estimation, simulation, propagation and channel characterization, computer networks, multiple access techniques, fiber optics, security and privacy and fading analysis. Others are; mobile computing, protocol performance evaluation, photonics switching, network architecture, cost benefit analysis of telecommunication systems and similar areas.

\section{Literature Review}

Impact factor has survived many criticisms despite the fact that it is the first bibliometric parameter created to evaluate journal articles [14]. The advent of CiteScore has helped to break the monopoly of impact factor and the combination of the two parameters is needed to effectively evaluate research activities using two different platforms. In addition, the h-index from Scopus database is now increasingly used to evaluate researchers for academic recruitment, promotions and grant assessment.

The issue of the transparency, comprehensive, reliable and timely evaluation of journals between the impact factor and CiteScore is often a major area of intense debate among the researchers [15-17]. Although the two have been adjudged far different from some untrusted and competing metrics [18]. The arguments have been on the capability of the bibliometric parameters to effectively evaluate journals within and outside the different subject areas [19-21], ensure maximum coverage while maintaining consistent impact measurement [22-24], avoid underrating the influence of smaller journals [25] and ensure adequate inclusion of conferences, books, book chapters and trade publications [26-27]. Both bibliometric parameters have been accused of focusing on journals with high impact factor or CiteScore without taking into consideration of other factors that can predispose authors into their choice of academic outlets [28]. For example, some authors may prefer to publish in journals of 
their core subject areas (areas of specialization) or association or university-based journals, which may not rank high based on impact factor or CiteScore. Hence, over dependence on the metrics can impair sound judgement on analysis and evaluation of scholarly output [29]. Measures are to be put in place to ensure that the metrics are applied appropriately and in an objective manner [30], especially in the presentation of the true quality of journals [31]. This will guide authors on tracking the growth and progress made by journals over a period [32].

Although, the two bibliometric parameters are related to their respective percentiles, the relationship is yet to graduate to predictive modelling for some subject area [33]. What that is available is when the relationship is considered for all the journals, which may not show the true picture. This is because of the following; firstly, citation patterns differ in different subject classification. Secondly, some journals have more than two subject classifications of which they can rank high in one and low in another [34]. Thirdly, there is uneven distribution of journals across the different subjects. Lastly, quartiles of journals are often different between the impact factor and CiteScore [35]. Percentiles therefore represent the viable alternative of predicting the two-bibliometric parameters.

\section{$3 \quad$ Materials and Methods}

Descriptive statistics were used to present the statistical moments of the impact factor (IF) and its journal percentile (JP (SCIE) and CiteScore and its percentile (JP (Scopus). Correlation and Curve estimation models were also used. The curve estimation models used are inverse, S, logarithmic, linear, quadratic, cubic, power, constant, growth, exponential and logistic. The model summary, analysis of variance (ANOVA) and coefficients of the models are computed to assess the model with the best fit. The models were applied in two separate cases using the IF and CiteScore as respective dependent variables and JP (SCIE) and JP (Scopus) as the respective independent variables. The models can be used in prediction of dependent variables using the independent variables.

\section{$4 \quad$ Results}

\subsection{Descriptive statistics, robust estimators and correlation}

The descriptive statistics for the impact IF, CiteScore, JP (SCIE), JP (Scopus) of the 89 telecommunications journals is presented in Table 1. The average and median CiteScore is greater than the impact factor. The same applies to the percentiles of the two metrics. The sum of the impact factors of the journals is less than the Scopus. The mean of the percentiles indicates that most of the journals are in the second quartile.

Table 2 presents the values of the Huber's M-estimator, Tukey's biweight, Hampel's M-estimator and Andrews' wave, which gave almost the same results for 
the median for all the metrics. This is an indication that there is presence of no outliers that can adversely affect the results of the curve estimation models.

Table 1. Descriptive Statistics for the IF, CiteScore, JP (SCIE), JP (Scopus) of the 89 Journals

\begin{tabular}{|l|c|c|c|c|}
\hline & IF & JP(SCIE) & CiteScore & JP(Scopus) \\
\hline Mean & 3.0783 & 52.2809 & 3.6921 & 71.8202 \\
\hline Median & 2.274 & 54 & 2.47 & 75 \\
\hline Std. Dev. & 3.0335 & 28.9451 & 4.2822 & 20.3601 \\
\hline Variance & 9.2024 & 837.8179 & 18.3371 & 414.5355 \\
\hline Kurtosis & 21.0191 & -1.2107 & 27.7114 & -0.1625 \\
\hline Skewness & 3.8325 & -0.0728 & 4.5542 & -0.6666 \\
\hline Minimum & 0.35 & 1 & 0.2 & 11 \\
\hline Maximum & 22.973 & 99 & 33.62 & 99 \\
\hline Sum & 273.967 & 4653 & 328.6 & 6392 \\
\hline
\end{tabular}

Table 2. Robust Estimators of IF, CiteScore, JP(SCIE), JP(Scopus) of the 89 Journals

\begin{tabular}{|l|c|c|c|c|}
\hline & Huber's M-Estimator & Tukey's Biweight & Hampel's M-Estimator & Andrews' Wave \\
\hline IF & 2.4094 & 2.2086 & 2.3350 & 2.2047 \\
\hline JP (SCIE) & 52.88 & 52.68 & 52.60 & 52.68 \\
\hline CiteScore & 2.6948 & 2.4665 & 2.6364 & 2.4644 \\
\hline JP (Scopus) & 74.11 & 74.43 & 73.54 & 74.45 \\
\hline
\end{tabular}

Strong significant positive correlations were obtained between impact factor and the CiteScore of the journals shown in Table 3. The same was obtained between JP (SCIE) and JP (Scopus) shown in Table 4.

Table 3. Correlation between IF and Citescore

\begin{tabular}{|l|c|c|}
\hline & Value & Significance (2-sided) \\
\hline Pearson's correlation & 0.908 & 0.000 \\
\hline Kendall's tau & 0.780 & 0.000 \\
\hline Spearman's rank & 0.904 & 0.000 \\
\hline
\end{tabular}

Table 4. Correlation between JP (SCIE) and JP (Scopus)

\begin{tabular}{|l|c|c|}
\hline & Value & Significance (2-sided) \\
\hline Pearson's correlation & 0.868 & 0.000 \\
\hline Kendall's tau & 0.752 & 0.000 \\
\hline Spearman's rank & 0.880 & 0.000 \\
\hline
\end{tabular}

\subsection{Curve estimation models}

Eleven curve estimation models were used. Curve estimation models were done in two parts. Firstly, is the case of estimating impact factor using JP(SCIE) and lastly, the estimation of CiteScore using JP(Scopus). 
The model summaries of the eleven curve estimation models were presented in increasing order of model fit in Table 5. Logistic, exponential, Growth and Compound models are the best models for predicting the impact factor using the journal percentile judging from their high values of R Square and Adjusted R Square and low values of the standard error of the estimates. The remaining seven models would present wrong predictions and high variance if used in estimating the impact factor because of their low values of R Square and Adjusted R Square and high values of the standard error of the estimates, despite that the models are significant as shown in Table 6. The coefficients of the four best fit models for estimating the impact factor using the journal percentile are presented as follows: compound model (Table 7), growth model (Table 8), exponential model (Table 9) and logistic model (Table 10).

Table 5. Model Summaries of Estimating Impact Factor using its Percentiles

\begin{tabular}{|l|c|c|c|}
\hline \multicolumn{1}{|c|}{ Model } & R Square & Adjusted R Square & Std. Error of the Estimate \\
\hline Inverse & 0.062 & 0.051 & 2.955 \\
\hline S & 0.296 & 0.288 & 0.632 \\
\hline Logarithmic & 0.304 & 0.296 & 2.545 \\
\hline Linear & 0.516 & 0.510 & 2.123 \\
\hline Quadratic & 0.654 & 0.646 & 1.805 \\
\hline Cubic & 0.755 & 0.746 & 1.529 \\
\hline Power & 0.805 & 0.803 & 0.335 \\
\hline Compound & 0.923 & 0.922 & 0.211 \\
\hline Growth & 0.923 & 0.922 & 0.211 \\
\hline Exponential & 0.923 & 0.922 & 0.211 \\
\hline Logistic & 0.923 & 0.922 & 0.211 \\
\hline
\end{tabular}

Table 6. Model Significance Summaries of Estimating Impact Factor using its Percentiles

\begin{tabular}{|l|c|c|}
\hline \multicolumn{1}{|c|}{ Model } & F & Significance \\
\hline Inverse & 5.768 & 0.018 \\
\hline S & 36.607 & 0.000 \\
\hline Logarithmic & 38.017 & 0.000 \\
\hline Linear & 92.715 & 0.000 \\
\hline Quadratic & 81.248 & 0.000 \\
\hline Cubic & 87.106 & 0.000 \\
\hline Power & 360.288 & 0.000 \\
\hline Compound & 1043.736 & 0.000 \\
\hline Growth & 1043.736 & 0.000 \\
\hline Exponential & 1043.736 & 0.000 \\
\hline Logistic & 1043.736 & 0.000 \\
\hline
\end{tabular}


Table 7. Coefficients of Compound Model of Estimating Impact Factor using its Percentiles

\begin{tabular}{|l|c|c|c|c|c|}
\hline \multirow{2}{*}{} & \multicolumn{2}{|c|}{ Unstandardized Coefficients } & $\begin{array}{c}\text { Standardized } \\
\text { Coefficients }\end{array}$ & \multirow{2}{*}{ t } & \multirow{2}{*}{ Sig. } \\
\cline { 2 - 5 } & $\boldsymbol{B}$ & Std. Error & Beta & & \\
\hline JP(SCIE) & 1.025 & 0.001 & 2.614 & 1288.894 & 0.000 \\
\hline (Constant) & 0.617 & 0.029 & & 21.597 & 0.000 \\
\hline \multicolumn{7}{|l}{ The dependent variable is $\ln (\mathrm{IF})}$. \\
\hline
\end{tabular}

Table 8. Coefficients of Growth Model of Estimating Impact Factor using its Percentiles

\begin{tabular}{|l|c|c|c|c|c|}
\hline \multirow{2}{*}{} & \multicolumn{2}{|c|}{ Unstandardized Coefficients } & $\begin{array}{c}\text { Standardized } \\
\text { Coefficients }\end{array}$ & \multirow{2}{*}{ t } & Sig. \\
\cline { 2 - 4 } & $\boldsymbol{B}$ & Std. Error & Beta & & \\
\hline JP(SCIE) & 0.025 & 0.001 & 0.961 & 32.307 & 0.000 \\
\hline Constant) & -0.484 & 0.046 & & -10.445 & 0.000 \\
\hline
\end{tabular}

Table 9. Coefficients of Exponential Model of Estimating Impact Factor using its Percentiles

\begin{tabular}{|c|c|c|c|c|c|}
\hline & \multicolumn{2}{|c|}{ Unstandardized Coefficients } & $\begin{array}{c}\text { Standardized } \\
\text { Coefficients }\end{array}$ & \multirow[t]{2}{*}{$\mathbf{t}$} & \multirow{2}{*}{ Sig. } \\
\hline & $B$ & Std. Error & Beta & & \\
\hline $\mathrm{JP}(\mathrm{SCIE})$ & 0.025 & 0.001 & 0.961 & 32.307 & 0.000 \\
\hline \begin{tabular}{|l} 
(Constant) \\
\end{tabular} & 0.617 & 0.029 & & 21.597 & 0.000 \\
\hline
\end{tabular}

Table 10. Coefficients of Logistic Model of Estimating Impact Factor using its Percentiles

\begin{tabular}{|c|c|c|c|c|c|}
\hline & \multicolumn{2}{|c|}{ Unstandardized Coefficients } & \multirow{2}{*}{$\begin{array}{c}\begin{array}{c}\text { Standardized } \\
\text { Coefficients }\end{array} \\
\text { Beta } \\
\end{array}$} & \multirow[t]{2}{*}{$\mathbf{t}$} & \multirow{2}{*}{ Sig. } \\
\hline & $B$ & Std. Error & & & \\
\hline $\mathrm{JP}(\mathrm{SCIE})$ & 0.975 & 0.001 & 0.383 & 1288.894 & 0.000 \\
\hline (Constant) & 1.622 & 0.075 & & 21.597 & 0.000 \\
\hline
\end{tabular}

The model summaries of the eleven curve estimation models for predicting the CiteScore using the journal percentile were presented in increasing order of model fit in Table 11. Logistic, exponential, Growth and Compound models are the best models by virtue of their high values of R Square and Adjusted R Square and low values of the standard error of the estimates. The remaining seven models (power, cubic, S, quadratic, linear, logarithmic and inverse) present average to poor fit, despite that the models are significant at 0.05 level of significance as shown in Table 12. The coefficients of the four best fit models for estimating the CiteScore using the journal percentile are presented as follows: compound model (Table 13), growth model (Table 14), exponential model (Table 15) and logistic model (Table 16). 
Paper - Curve Estimation Models for Estimation and Prediction of Impact Factor and CiteScore ..

Table 11. Model Summaries of Estimating CiteScore using its Percentiles

\begin{tabular}{|l|l|l|l|}
\hline Model & R Square & Adjusted R Square & Std. Error of the Estimate \\
\hline Inverse & & & \\
\hline 0.108 & 0.097 & 4.068 & \\
\hline 0.240 & 0.231 & 3.756 & \\
\hline 0.343 & 0.336 & 3.490 & \\
\hline 0.479 & 0.466 & 3.128 & \\
\hline 0.512 & 0.506 & 0.556 & \\
\hline 0.562 & 0.547 & 2.884 & \\
\hline 0.768 & 0.765 & 0.383 & \\
\hline 0.857 & 0.855 & 0.301 & \\
\hline 0.857 & 0.855 & 0.301 & \\
\hline 0.857 & 0.855 & 0.301 & \\
\hline 0.857 & 0.855 & 0.301 & \\
\hline
\end{tabular}

Table 12. Model Significance Summaries of Estimating CiteScore using its Percentiles

\begin{tabular}{|l|c|c|}
\hline \multicolumn{1}{|c|}{ Model } & F & Significance \\
\hline Inverse & 10.496 & 0.002 \\
\hline Logarithmic & 27.408 & 0.000 \\
\hline Linear & 45.448 & 0.000 \\
\hline Quadratic & 39.472 & 0.000 \\
\hline S & 91.198 & 0.000 \\
\hline Cubic & 36.354 & 0.000 \\
\hline Power & 288.113 & 0.000 \\
\hline Compound & 521.761 & 0.000 \\
\hline Growth & 521.761 & 0.000 \\
\hline Exponential & 521.761 & 0.000 \\
\hline Logistic & 521.761 & 0.000 \\
\hline
\end{tabular}

Table 13. Coefficients of Compound Model of Estimating CiteScore using its Percentiles

\begin{tabular}{|l|c|c|c|c|c|}
\hline \multirow{2}{*}{} & \multicolumn{2}{|c|}{ Unstandardized Coefficients } & $\begin{array}{c}\text { Standardized } \\
\text { Coefficients }\end{array}$ & \multirow{2}{*}{ T } & \multirow{2}{*}{ Sig. } \\
\cline { 2 - 5 } & $\boldsymbol{B}$ & Std. Error & Beta & & \\
\hline JP(Scopus) & 1.037 & 0.002 & 2.524 & 634.583 & 0.000 \\
\hline (Constant) & 0.197 & 0.023 & & 8.504 & 0.000 \\
\hline
\end{tabular}


Paper-Curve Estimation Models for Estimation and Prediction of Impact Factor and CiteScore ...

Table 14. Coefficients of Growth Model of Estimating CiteScore using its Percentiles

\begin{tabular}{|l|c|c|c|c|c|}
\hline \multirow{2}{*}{} & \multicolumn{2}{|c|}{ Unstandardized Coefficients } & $\begin{array}{c}\text { Standardized } \\
\text { Coefficients }\end{array}$ & \multirow{2}{*}{ T } & \multirow{2}{*}{ Sig. } \\
\cline { 2 - 4 } & $\boldsymbol{B}$ & Std. Error & Beta & & \\
\hline JP(Scopus) & 0.036 & 0.002 & 0.926 & 22.842 & 0.000 \\
\hline (Constant) & -1.622 & 0.118 & & -13.795 & 0.000 \\
\hline
\end{tabular}

Table 15. Coefficients of Exponential Model of Estimating CiteScore using its Percentiles

\begin{tabular}{|l|l|l|l|l|l|}
\hline \multirow{2}{*}{} & \multicolumn{2}{|c|}{ Unstandardized Coefficients } & $\begin{array}{c}\text { Standardized } \\
\text { Coefficients }\end{array}$ & \multirow{2}{*}{ T } & \multirow{2}{*}{ Sig. } \\
\cline { 2 - 5 } & \multicolumn{1}{|c|}{$\boldsymbol{B}$} & \multicolumn{1}{|c|}{ Std. Error } & Beta & & 0.000 \\
\hline JP(Scopus) & 0.036 & 0.002 & 0.926 & 22.842 & 0.000 \\
\hline Constant) & 0.197 & 0.023 & & 8.504 & \\
\hline The dependent variable is ln (CiteScore).
\end{tabular}

Table 16. Coefficients of Logistic Model of Estimating CiteScore using its Percentiles

\begin{tabular}{|l|c|c|c|c|c|}
\hline \multirow{2}{*}{} & \multicolumn{2}{|c|}{ Unstandardized Coefficients } & $\begin{array}{c}\text { Standardized } \\
\text { Coefficients }\end{array}$ & \multirow{2}{*}{ T } & \multirow{2}{*}{ Sig. } \\
\cline { 2 - 4 } & $\boldsymbol{B}$ & Std. Error & Beta & & \\
\hline JP(Scopus) & 0.965 & 0.002 & 0.396 & 634.583 & 0.000 \\
\hline (Constant) & 5.064 & 0.595 & & 8.504 & 0.000 \\
\hline
\end{tabular}

\section{Conclusion}

The paper has successfully obtained predictive models for predicting impact factor and CiteScore using journal percentiles extending the observed correlation between the metrics to predictive models. The coefficients of the percentiles in the various models is significant and the best models guarantee minimum errors between the actual and predicted values. The research can be extended to other bigger subject classifications.

\section{Acknowledgement}

The support from Covenant University is greatly appreciated.

\section{$7 \quad$ References}

[1] Brown, T. \& Gutman, S.A. (2019). Impact factor, eigenfactor, article influence, scopus SNIP, and SCImage journal rank of occupational therapy journals. Scand. J. Occupat. Therapy, 26(7), 475-483. https://doi.org/10.1080/11038128.2018.1473489 
[2] Liu, J. \& Li, S. (2015). Research on the ranking of university education based on GreyTOPSIS-DEA method. Int. J. Emerging Tech. Learn., 10(8), 51-54. https://doi.org/10. 3991/ijet.v10i8.5279

[3] Okagbue, H.I., Atayero, A.A., Oguntunde, P.E., Opanuga, A.A., Adamu, P.I. \& Adebayo, A.O.I. (2018). Exploration of Research Areas of Universities in Nigeria based on Scopus Subject Document Classification. Int. J. Educ. Info. Technol., 12, 117-123.

[4] Omar, M.F. (2019). Towards designing tools for universities? R\&D performance measurement on mobile platform. Int. J. Interactive Mobile Technol., 13(4), 178-187. https://doi.org/10.3991/ijim.v13i04.10547

[5] Okagbue, H.I., Opanuga, A.A., Oguntunde, P.E., Adamu, P.I., Iroham, C.O. \& Adebayo, A.O.I. (2018). Research Output Analysis for Universities of Technology in Nigeria. Int. J. Educ. Info. Technol., 12, 105-109.

[6] Alwraikat, M. (2017). Smartphones as a new paradigm in higher education overcoming obstacles. Int. J. Interactive Mobile Technol., 1(4), 114-135. https://doi.org/10.3991/ ijim.v11i4.6759

[7] Okagbue, H.I., Atayero, A.A., Adamu, M.O., Bishop, S.A., Oguntunde, P.E. \& Opanuga, A.A. (2018). Exploration of editorial board composition, Citescore and percentiles of Hindawi journals indexed in Scopus. Data in Brief, 19, 743-752. https://doi.org/10.1016/i.dib.2018.05.066

[8] Momeni, Z. \& Azizi, A. (2018). Current order and inventory models in manufacturing environments: A review from 2008 to 2018. Int. J. Online Engine., 14(6), 223-248. https://doi.org/10.3991/ijoe.v14i06.8055

[9] Okagbue, H.I., Atayero, A.A., Adamu, M.O., Oguntunde, P.E., Opanuga, A.A. \& Adamu, P.I. (2018). Analysis of dataset on editorial board composition of Dove Medical Press by continent. Data in Brief, 20, 1440-1445. https://doi.org/10.1016/j.dib.2018.08.196

[10] Villaseñor-Almaraz, M., Islas-Serrano, J., Murata, C. \& Roldan-Valadez, E. (2019). Impact factor correlations with Scimago Journal Rank, Source Normalized Impact per Paper, Eigenfactor Score, and the CiteScore in Radiology, Nuclear Medicine \& Medical Imaging journals. Radiol. Medica, 124(6), 495-504. https://doi.org/10.1007/s11547-019$\underline{\text { 00996-z }}$

[11] Okagbue, H.I., Atayero, A.A., Adamu, M.O., Oguntunde, P.E., Opanuga, A.A. \& Bishop, S.A. (2018). Dataset and analysis of editorial board composition of 165 Hindawi journals indexed and abstracted in PubMed based on affiliations. Data in Brief, 19, 520-525. https://doi.org/10.1016/j.dib.2018.05.065

[12] Halim, Z. \& Khan, S. (2019). A data science-based framework to categorize academic journals. Scientometrics, 119(1), 393-423. https://doi.org/10.1007/s11192-019-03035-w

[13] Okagbue, H.I., Atayero, A.A., Adamu, M.O., Opanuga, A.A., Oguntunde, P.E. \& Bishop, S.A. (2018) Dataset on statistical analysis of editorial board composition of Hindawi journals indexed in Emerging sources citation index, Data in Brief, 17, 1041-1055. https://doi.org/10.1016/j.dib.2018.02.044

[14] La Torre, G., Sciarra, I., Chiappetta, M. \& Monteduro, A. (2017). New bibliometric indexes in scientific literature: A constantly evolving panorama. Clinica Terapeutica, 168(2), 65-71.

[15] Šterbenc, A. \& Oštrbenk, A. (2017). Elsevier's citescore index values for acta dermatovenerologica, alpina, Pannonica et Adriatica: A 2016 update. Acta Dermat. Alpina, Pann. Adria., 26(3), 53. https://doi.org/10.15570/actaapa.2017.17

[16] Poljak, M. (2017). Coverage of acta dermatovenerologica alpina, pannonica et adriatica in elsevier's citescore index: A new tool for measuring the citation impact of academic 
journals. Acta Dermat. Alpina, Pann. Adria., 26(1), 10.15570/actaapa.2017.1. https://doi.org/10.15570/actaapa.2017.1

[17] Ranjan, C.K. (2017). Bibliometric indices of scientific journals: Time to overcome the obsession and think beyond the impact factor. Med. J. Armed Forces India, 73(2), 175177. https://doi.org/10.1016/j.mjafi.2017.03.008

[18] Teixeira da Silva, J.A. \& Memon, A.R. (2017). CiteScore: A cite for sore eyes, or a valuable, transparent metric? Scientometrics, 111(1), 553-556. https://doi.org/10.1007/ s11192-017-2250-0

[19] Colledge, L., James, C., Azoulay, N., Meester, W. \& Plume, A. (2017). CiteScore metrics are suitable to address different situations - A case study. Euro. Sci. Edit., 43(2), 27-31. https://doi.org/10.20316/ESE.2017.43.003

[20] Walters, W.H. (2017). Do subjective journal ratings represent whole journals or typical articles? Unweighted or weighted citation impact? J. Informetrics, 11(3), 730-744. https://doi.org/10.1016/i.joi.2017.05.001

[21] Mendes, A.M., Tonin, F.S., Buzzi, M.F., Pontarolo, R. \& Fernandez-Llimos, F. (2019). Mapping pharmacy journals: A lexicographic analysis. Res. Soc. Admin. Pharm., 10.1016/j.sapharm.2019.01.011. https://doi.org/10.1016/j.sapharm.2019.01.011

[22] Avena, M.J. \& Barbosa, D.A. (2017). Bibliometric indicators of the nursing journals according to the index databases. Rev. Escola de Enfermagem, 51, Art. no. e03262. https://doi.org/10.1590/s1980-220x2017014603262

[23] Dove, C., Chan, T.M., Thoma, B., Roland, D. \& Bruijns, S.R. (2019). A cross-sectional description of open access publication costs, policies and impact in emergency medicine and critical care journals. Afr. J. Emer. Medic., https://doi.org/10.1016/j.afjem.2019.01.015

[24] Zhang, Y., Thenkabail, P.S. \& Wang, P. (2019). A bibliometric profile of the Remote Sensing Open Access Journal published by MDPI between 2009 and 2018. Remote Sensing, 11(1), Art. no. 91. https://doi.org/10.3390/rs11010091

[25] Vrabel, M. (2019). Beyond the Impact Factor. Oncol. Nurs. Forum, 46(2), 143-145. https://doi.org/10.1188/19.ONF.143-145

[26] Meho, L.I. (2019). Using Scopus's CiteScore for assessing the quality of computer science conferences. J. Informetrics, 13(1), 419-433. https://doi.org/10.1016/j.joi.2019.02.006

[27] Varada Rajkumar, K., Adimulam, Y. \& Subrahmanyam, K. (2018). A critical study and analysis of journal metric "CiteScore", cluster and regression analysis. Int. J. Engine. Technol., 7(2), 28-32. https://doi.org/10.14419/ijet.v7i2.7.10251

[28] Dozmorov, M.G. (2018). GitHub statistics as a measure of the impact of open-source bioinformatics software. Front. Bioengine. Biotech., 6(DEC), Art. no. 198. https://doi.org/10.3389/fbioe.2018.00198

[29] Kim, K. \& Chung, Y. (2018). Overview of journal metrics. Sci. Edit., 5(1), 16-20. https://doi.org/10.6087/kcse.112

[30] Manolopoulos, Y. \& Katsaros, D. (2017). Metrics and rankings: Myths and fallacies. Commun. Comp. Info. Sci., 706, 265-280. https://doi.org/10.1007/978-3-319-57135-5 19

[31] Al-Hoorie, A.H. \& Vitta, J.P. (2018). The seven sins of L2 research: A review of 30 journals' statistical quality and their CiteScore, SJR, SNIP, JCR Impact Factors. Lang. Teach. Res., https://doi.org/10.1177/1362168818767191

[32] Huerta, M.A., De Jesus, M. \& Cabello-Pasini, A. (2019). A bibliometric analysis for ciencias marinas 45 years after its inception. Ciencias Marinas, 45(1), 17-22. https://doi.org/10.7773/cm.v45i1.2993

[33] Varada Rajkumar, K. Email Author, Yesubabu, A. \& Subrahmanyam, K. (2018). Regression and validation analysis on a citescore dataset. J. Adv. Res. Dynam. Control Syst., 10(5), 265-275. 
[34] Gedda, M. (2018). Bibliometric indices and French-language physiotherapy journals. Kinesitherapie, 18(198), 9-28. https://doi.org/10.1016/j.kine.2018.02.004

[35] Fernandez-Llimos, F. (2018). Differences and similarities between journal impact factor and citescore. Pharm. Pract., 16(2), Art. no. 1282.https://doi.org/10.18549/ $\underline{\text { PharmPract.2018.02.1282 }}$

\section{Authors}

Hilary I. Okagbue is a Faculty at Covenant University, Ota, Nigeria. Areas of specialization are Data Science, Mathematical Statistics and Statistical Learning. Email id: hilary.okagbue@ covenantuniversity.edu.ng

Patience I. Adamu is a Senior Faculty at Covenant University, Ota, Nigeria. Areas of specialization are Optimization, Statistical Data Analysis and Algorithms.

Sheila A. Bishop is a Senior Faculty at Covenant University, Ota, Nigeria. Areas of specialization are Stochastic Analysis, Mathematical Statistics and Differential Equations.

Emmanuela C.M. Obasi is a Faculty at Federal University, Otuoke, Nigeria. Areas of specialization are Data Mining, Computer Security and Database management.

Adedotun O. Akinola is a Faculty at Covenant University, Ota, Nigeria. Areas of specialization are Urban and Regional planning and Housing satisfaction.

Article submitted 2019-06-25. Resubmitted 2019-08-17. Final acceptance 2019-08-18. Final version published as submitted by the authors. 